\title{
Editorial for Minds and Machines Special Issue on Philosophy of Colour
}

\author{
M. Chirimuuta ${ }^{1}$
}

Received: 17 June 2015/Accepted: 17 June 2015/Published online: 1 July 2015

(C) Springer Science+Business Media Dordrecht 2015

This special issue of Minds and Machines presents new work in the philosophy of colour. While this research is informed by recent findings in the colour sciences, it grapples with one of the perennial disputes in metaphysics: what kinds of properties are the colours and where, if anywhere, are they instantiated? The dispute typically takes the form of a weighing of the costs and benefits of one of the core theories in colour ontology. In this editorial I will give a brief overview of background debates, summarise the main points of the articles assembled here, and comment on some of their interconnected themes.

Let's first look back on the recent history of the colour debate. Hardin (1988) marshalled results from colour psychophysics to argue that chromatic properties are in fact never instantiated and should be eliminated from our ontological inventory. Almost simultaneously Hilbert (1987) proposed that colours are actually spectral surface reflectances (SSR's) - physical properties as real as any other (cf. Matthen 1988; Byrne and Hilbert 2003). Much of the literature of that time was taken up with the dialectic between these two views. In comparison with the debate of 20 years ago the papers showcased here reflect the centrality of colour relationism to current discussions. Relationism, can be thought of as a middle path between Hardin's eliminativism and Hilbert's physicalism. It is the idea that colours are real (instantiated) properties but unlike ordinary physical properties they are in some sense perceiver-related (Thompson 1995; Cohen 2004, 2009).

Why should one be a relationist about colour? A standard argument comes from phenomena of perceptual variation. An extreme example of colour visual variation gripped the world's attention back in February this year. As Gegenfurtner et al.

M. Chirimuuta

mac289@pitt.edu

1 University of Pittsburgh, Pittsburgh, PA, USA 
(2015) write at the end of their study on the variety of colour percepts elicited by "\#The Dress",

our perception of the world is not just a result of physical properties recorded by our senses. Rather, we make assumptions about the world that guide the interpretation of sensory data, and these assumptions can be quite different for different individuals.

The implication is that colour-understood as a chromatic property figuring in our perceptual experience-is in some sense dependent on the perceiver, and thus colours are liable to be different due to differences amongst individuals. But why should perceptual variability imply perceiver dependence?

It is worth turning to explore the deeper history of the debate. Colour is the prototypical example of a secondary quality. In the seventeenth century when the primary-secondary quality distinction was baptised, primary qualities (e.g. shape or "figure", motion, mass) were taken to be the basic and inherent properties of matter which were crucial to physical explanation, whereas secondary qualities (colour, taste, warmth, cold, smell, sound) were variously theorised as mere sensations, or the dispositions of objects to provoke such sensations.

In the Essay Concerning Human Understanding Locke includes an argument from perceptual variation in his famous exposition of the primary-secondary distinction:

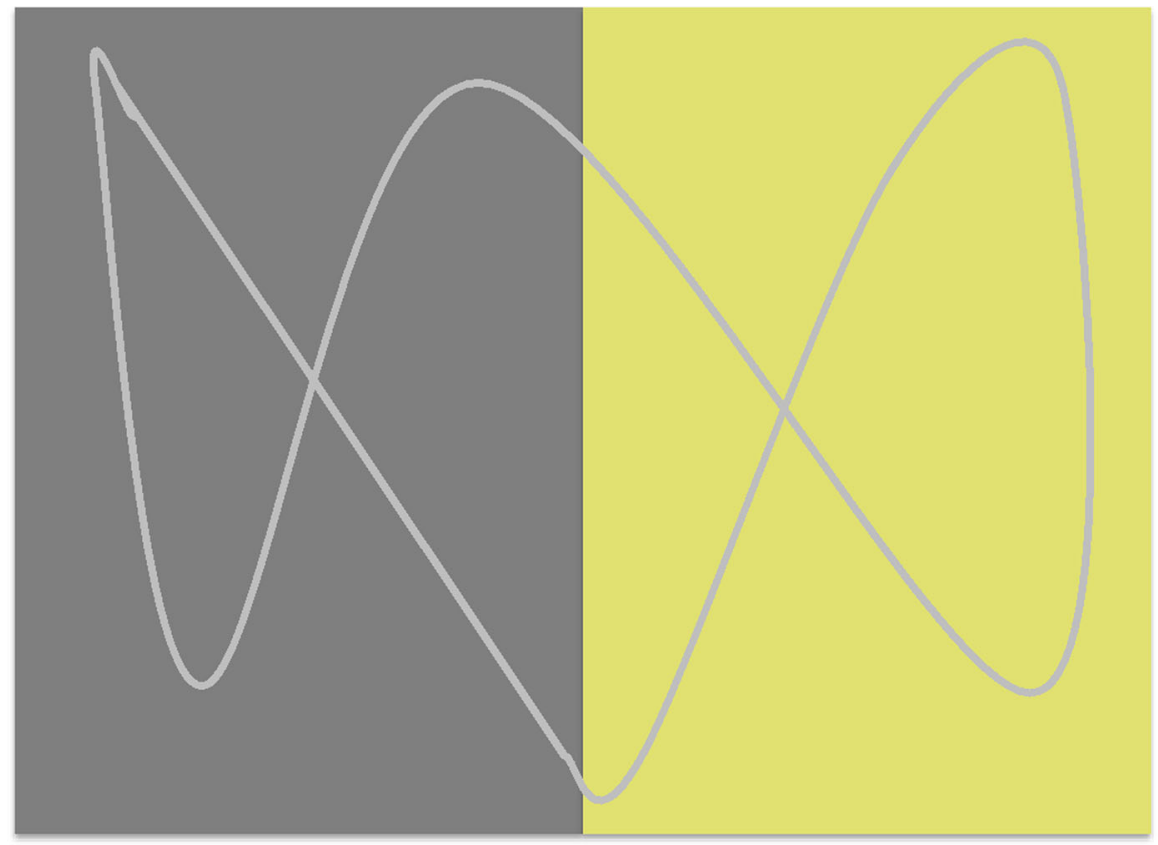

Fig. 1 Simultaneous colour contrast 
we may be able to give an account how the same water, at the same time, may produce the idea of cold by one hand and of heat by the other whereas it is impossible that the same water, if those ideas were really in it, should at the same time be both hot and cold. For if we imagine warmth as it is in our hands to be nothing but a certain sort and degree of motion in the minute particles of our nerves, or animal spirits, we may understand how it is possible that the same water may at the same time produce the sensation of heat in one hand and cold in the other; which yet figure never does, that never producing the idea of a square by one hand which has produced the idea of a globe by another. (Locke 1690/1993, Bk II chap viii, \$21)

The basic idea is that the perceiver-dependency of warmth and coolness explains the variability of sensations elicited by the very same sample of water. Yet an alternative explanation-one which would be compatible with the perceiver independence of warmth and coolness-is simply that one hand misperceives the temperature. It is telling that Locke claims that perceptions of shape are not subject to such variability. And yet a common observation is that the shape of objects appears to vary with viewing angles. So what is the particular issue with secondary qualities?

I suggest that for the primary qualities we have a strong intuition that there is one correct and independently verifiable answer to the question, e.g., 'what is the actual shape of this object?' For colour, situations arise in which there is no one indisputably correct answer. A case in point would be an image such as Fig. 1. ${ }^{1}$ With this effect, known as simultaneous colour contrast, the hue and lightness of the squiggle appears different depending on the background colour. If one looks at the squiggle just at the border between the two backgrounds it also seems as if there is a border within the squiggle, even though its pixel values are actually unchanged. If colours are intrinsic properties of surfaces and pixels (as colour realism asserts), then the colour of the pixels cannot be subject to alteration as the background changes. So which is the actual colour of the squiggle? Is it the pure whitish grey, as seen on the left hand side, or the darker, purpley shade? We cannot simply say that one or other of the backgrounds - either the achromatic one or the yellow oneprovides the ideal conditions for viewing the true colour of the squiggle, lest we be forced to conclude that we are often subject to illusions in everyday life, each time we view items against the non-ideal background.

In his book, The Red and the Real, Jonathan Cohen's "Master Argument" for colour relationism proceeds in these four steps:

1. “There are multiple, psychophysically distinguishable, perceptual effects (in respect of color) of a single color stimulus.

2. There is no independent and well-motivated reason for thinking that just one of the variants catalogued at step 1 is veridical (at the expense of the others).

\footnotetext{
1 \#The Dress is not a good example here because when seen in real life it is reported to appear unambiguously blue and black. Which suggests that those who see the dress in the photo as white and gold are misperceiving its colours (see discussion below regarding Cohen's treatment of disagreement in this special issue). Still, it would be fair to say that the photograph, by itself, is a genuinely ambiguous image.
} 
3. Given that there is no well-motivated reason for singling out any single variant as veridical (at the expense of the others), an ecumenical reconciliation of the variants is preferable to an unmotivated stipulation in favour of just one of them.

4. The best way to implement such an ecumenical reconciliation between apparently incompatible variants is to view them as the result of relativizing colors to different values of certain parameters, which is just to admit that colors are relations between objects and those parameters." (Cohen 2009, 24; and see Cohen 2015, §1.1)

This argument is most troubling for reductive colour realists (physicalists) who, following Hilbert (1987), identify colours with certain sets of SSR's or "productances" in the case of luminous and transparent colours. Since the physical properties of the squiggle do not change from one context to another, physicalists are forced to bite the bullet and say that one of the colour appearances is nonveridical, but yet we have no way of knowing which (Byrne and Hilbert 2003, 17). ${ }^{2}$

In this issue, Berit Brogaard presents an overview of the psychological literature on variation in colour vision amongst supposedly normal (trichromatic) subjects. For instance, there is wide dispute in perception of the unique hues and no perceiver-independent grounds for favouring one uniqueness judgement over another. ${ }^{3}$ Brogaard also discusses more exotic sources of variable colour experience, such as the "alien colours" associated with synaesthesia and possible tetrachromacy in the female relatives of dichromatic or colour-blind men.

The central point of Brogaard's article is that a theory in the vicinity of relationism, the self locating property view (AKA relativism) does as good a job as relationism in handling the cases of perceptual variation, and is to be preferred for further reasons. The idea is that colours are self-locating (or "centred") properties of the form being qualitative yellow/orange, etc. These properties can be instantiated by an object only relative to a centred world-a world in which a person, a time and perhaps a perceptual circumstance is marked. So, the same wallpaper may be pale yellow relative to a centred world in which I occupy the centre but peach-coloured relative to a world around which my more sophisticated cousin is centred.

To see the difference between relationism and the self locating property theory, it is worth borrowing an example from Brogaard (2011):

if this chili instantiates the centered property being tasty only relative to an assessor, and the chili is tasty relative to assessor E1, then it instantiates the uncentered [relational] property being-tasty-relative-to-assessor-E1 relative to the world as a whole. ..... This chili has the centered property of being tasty only relative to someone who considers the quality of the chili but it has the situation-dependent [i.e. relational] property being-tasty-relative-to-me

\footnotetext{
${ }^{2}$ Non-reductive colour realists (primitivists) appeal to pluralist colour ontologies in response to this argument (Kalderon 2007).

${ }^{3}$ The problem of uniqueness was also debated in the pages of Analysis by Tye (2006a, b, 2007), Cohen et al. (2006, 2007), Byrne and Hilbert (2007) and Matthen (2009).
} 
relative to the world as a whole. So, while objects have centered properties only relative to individuals (and/or other marked features), objects have situation-dependent [relational] properties from a God's eye point of view.

On Cohen's view, colours are the relational or "situation-dependent" properties, whereas on Brogaard's view colours are the centred properties.

Even though the difference between these two theories is subtle, Brogaard argues that we can see daylight between them if we consider the phenomenology of colour vision. Assuming that colour visual experience represents objects as having colours, if colours are relational properties then all of the relata (perceivers, perceptual circumstances) should, on Brogaard's analysis, be represented in visual experience. Yet this is not by any stretch an obvious feature of colour experience. Since the selflocating property view does not have this implication, it is apparently more consistent with manifest colour experience. Another point in favour of the selflocating theory is that it is prima facie possible for two different perceivers to have identical colour experiences. Yet on the relational view the properties being represented in colour experience-the properties on which colour visual experience supervenes-are necessarily related to perceivers, so it follows that you and I could never have exactly the same chromatic experience.

In my brief sketch of the argument from perceptual variation I omitted discussion of one wrinkle for the relationist. For each case of variability for which an ecumenical resolution is preferable, one can find examples which are more naturally analysed as genuine disagreements. That is, instances in which it is natural to say that one party perceives the stimulus correctly and the other is mistaken, that their judgments are comparable and mutually incompatible. Take the case of \#The Dress. People were not content to say, ecumenically, that the dress is white-and-gold-forus, and blue-and-black-for-you, and that those colour attributions were actually not comparable because indexed to different perceivers. Rather, there was a sense of genuine disagreement about the colours of the fabric as depicted in the photo.

The primary purpose of Cohen's contribution is to show how relationism can accommodate cases of disagreement over comparable colour ascriptions. The proposal is to draw on the idea of coarse-grained colours first developed by Cohen (2009). Colour predicates are not apparently indexed to perceivers and viewing circumstances and this suggests that at the cognitive/linguistic, rather than perceptual level we represent colours in a coarser grained, non-relational way. Judgements about these colours may be comparable and incompatible.

Cohen's second task is to consider the relative merits of relationism and the self locating property view. Cohen concurs with Brogaard's assessment that the two theories are substantially different, and not just notational variants. For Cohen, the key thing is that the relationist is committed to a metaphysics of colour whereby these properties are inherently perceiver-involving, while the self locating property theory is agnostic here. This, Cohen argues, is a reason to prefer relationism.

While advocates of relationism and relativism tend to emphasise the numerous cases of perceptual variability, their realist antagonists prefer to concentrate on the many instances of colour constancy. In the familiar dialectic, constancy phenomena are taken to support reductive realism/physicalism (Tye 2000, 147) or primitivism 
(Allen 2007) and instances of variability are said to support relationism (Cohen 2009), relativism (Brogaard 2015) or anti-realism (Hardin 1988). This raises an important question about which kinds of phenomena are more prevalent, and whether seeming cases of variability are actually instances of constancy (or vice versa).

This issue is taken up here by Derek Brown (2015), who has elsewhere defended the colour layering thesis, that "we can experience two colours along a single line of sight, one (opaque) colour through the other (transparent) colour" $(2014,2)$. Cohen's master argument uses the example of centre-surround contrast (see Fig. 1 above) to convey the need for an ecumenical resolution to the problem of colour variability. Cohen then asserts that the same relationist solution is applicable to numerous other kinds of variation, such as those due to differences in perceiver and also what Brown calls "line-of-sight relativities"-instances in which the target colour appears to vary due to the presence of objects in front of or behind it. For example, Fig. 2 represents a case in which the yellow of the smiley face varies depending on whether a grey transparent filter (like a sunglass lens) stands in the line of sight to the face.

The purpose of Brown's article is to argue that a scenario such as that depicted in Fig. 2 need not be characterized in relationist terms. That is, we need not say that the smiley face has different context-relative colours when viewed by itself and through the sunglasses. Brown's layering alternative is to say that the surface bears one opaque yellow, part of which is seen through the transparent grey of the lens.

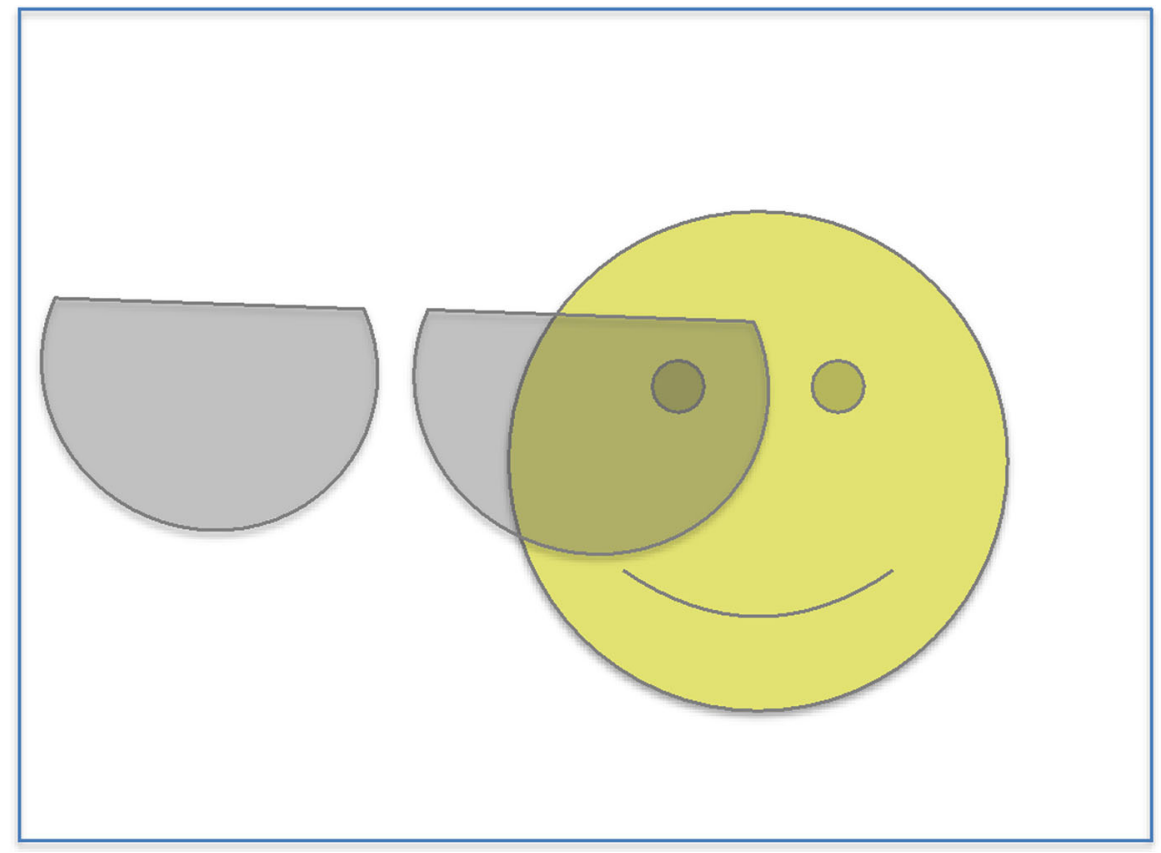

Fig. 2 Illustration of line-of-sight colour relativity 
Brown argues that it is therefore premature to give a uniform relationist treatment to the line-of-sight relativities, and this raises the question of how expansive the evidence base for relationism really is.

Keith Allen's (2015) contribution brings us to the internecine dispute between reductive and non-reductive colour realists. Another feature of recent work on colour ontology is the popularity of non-reductive realism (aka primitivism). Like their physicalist counterparts, primitivists believe that colours are mind-independent properties instantiated in visible objects around us; but they deny that colours can be identified with or reduced to any kinds of physical property such as SSR. Examples of perceptual variation without obvious error (e.g. Fig. 1) cause problems for both kinds of realists. Here Allen argues that consideration of the structural properties of colour gives primitivism the edge over physicalism.

By structural properties, Allen and others such as Hardin (1988) and Johnston (1992) avert to the fact that e.g. canary yellow is more similar to the colour orange than it is to royal blue. On Allen's (2015) formulation, the argument against physicalism proceeds as follows:

1. "The structural properties of the colours are essential properties of the colours;

2. There are no physical properties of things in the environment that instantiate the structural properties of the colours;

3. If colours are physical properties of things in the environment, then everything that is true essentially of the colours is true essentially of these physical properties;

4. Therefore, colours are not physical properties of things in the environment."

In order to address this kind of objection, Byrne and Hilbert (2003) and Byrne (2003) propose that colour experiences represent objects as instantiating different proportions of hue magnitudes, R, G, B and Y. For example, an object such as a ripe satsuma instantiates a binary hue-orange-which could be represented as having values of $\mathrm{R}$ and $\mathrm{Y}$ that are each $50 \%$ of its total hue. Allen draws on experimental studies of hue identification in the NCS colour space which show that the task of analyzing colours into four or six (including black and white) elementary hues is surprisingly difficult for untrained subjects. This casts doubt on Byrne and Hilbert's assertion that all colour experiences ordinarily represent objects in terms of such primitives.

Allen's paper brings us to the interesting question of methodology-how can the philosophy of colour best make use of the findings of colour science? Primitivism has its origins in the Oxford tradition of ordinary language philosophy. As such, its original impetus was not a naturalistic one. In other words, the aim was to underwrite everyday concepts of colour by drawing on the resources of ordinary language and experience, rather than any body of scientific knowledge. Here, however, Allen is making use of empirical results on colour spaces in order to argue for the superiority of primitivist realism over its physicalist, and more traditionally naturalistic rival. This more science-facing approach to primitivism is of a piece with Allen's other work (2009) on comparative colour vision, and also work by Gert 
(2008, 2010) and Watkins (2002). In this contribution Allen also argues against naturalistically motivated objections to primitivism such as causal over-determination (cf. Watkins 2005), and the idea that colours are in some sense subjective because we must appeal to the brain and visual system to explain certain facts about colour (Hardin 1988). In short, even the positions in colour ontology which were once furthest removed from empirical concerns are now engaged in the naturalistic programme.

A thing that is clear from the range of papers collected here, all drawing on colour science in quite different ways, is that one cannot develop a naturalistic philosophy of colour simply by reading off the theoretical commitments of colour science. So it is important to find other ways to characterise the naturalistic methodology. One strategy is to mine specialized seams of experimental science which are rich in philosophical interest and relatively unexploited. In such cases we can think of empirical research as a raw material for philosophical enquiry-a source of constraints on proposed theories and counter-examples to commonly held intuitions. Brown's work on layering and scission is an example here, and this is also the agenda behind my paper co-authored with Fred Kingdom.

Compared to 25 years ago, a new focus of vision science is research on interactions between colour and other visual modalities. For example, colour vision has been shown to be important for the perception of form, depth, shadows and material (Shevell and Kingdom 2008). This is suggestive of the idea that colour vision has many functions besides allowing individuals to recognise hue. In this issue, Chirimuuta and Kingdom (2015) provide a brief review of the existing literature and discuss some very recent findings showing how luminance contrast affects the perception of form in stereoscopic vision. We argue that in comparison with rival theories of colour, an adverbialist ontology (Chirimuuta 2015) — a variety of relationism which attributes colours to perceptual processes rather than objects or perceivers - is best able to accommodate the multi-functionality of colour vision.

In one of the few papers that deals explicitly with methodological issues in this area, Johnson and Wright $(2006,140)$ offer a Quinean indispensability argument for colour realism, noting that theories of colour should be shaped directly by scientific concerns. They write that,

a metaphysical theory of color that is designed to be of use in the sciences should be driven largely (or perhaps entirely) by considerations of what the various sciences need in order to proceed appropriately.

Without endorsing Johnson and Wright's methodological prescription, of the papers gathered in this special issue it is still interesting to ask whether their theoretical proposals could be put to work within any empirical research programmes; and if so, how and in which particular contexts.

It will be interesting to see what the future holds for the philosophy of colour. Elsewhere in the philosophy of perception there has been an increasing interest in the non-visual modalities-touch, sound, taste and smell (see e.g. Stokes et al. 2014). There is much potential for useful integration of these areas of research. While colour is treated as the exemplary secondary quality, it could well be that thought on the matter has been unwittingly shaped by the peculiar characteristics of 
visual perception. Perhaps a different kind of secondary quality ontology will come to the fore once equal consideration is given to the other modalities.

To conclude this editorial, I would like to offer warm thanks to all of the authors who contributed to this issue for their timely, rich and original contributions. I am also very grateful to the anonymous reviewers who provided much helpful feedback, and to Greg Wheeler for the invitation to put together the issue.

\section{References}

Allen, K. (2007). The mind-independence of colour. European Journal of Philosophy, 15(2), 137-158.

Allen, K. (2009). Inter-species variation in colour perception. Philosophical Studies, 142, 197-220.

Allen, K. (2015). Colour physicalism, naïve realism, and the argument from structure. Minds and Machines. doi:10.1007/s11023-014-9353-7.

Brogaard, B. (2011). Centered worlds and the content of perception. In S. D. Hales (Ed.), Blackwell companion to relativism (pp. 137-158). Chichester: Wiley.

Brogaard, B. (2015). The self-locating property theory of color. Minds and Machines. doi:10.1007/ s11023-015-9373-y.

Brown, D. (2014). Colour layering and colour constancy. Philosopher's Imprint, 14(15).

Brown, D. (2015). Colour layering and colour relationism. Minds and Machines. doi:10.1007/s11023015-9363-0.

Byrne, A. (2003). Color and similarity. Philosophy and Phenomenological Research, 66(3), 641-665.

Byrne, A., \& Hilbert, D. R. (2003). Color realism and color science. Behavioral and Brain Sciences, 26, 3-64.

Byrne, A., \& Hilbert, D. R. (2007). Truest blue. Analysis, 67(1), 87-92.

Chirimuuta, M. (2015). Outside color: Perceptual science and the puzzle of color in philosophy. Cambridge MA: MIT press.

Chirimuuta, M., \& Kingdom, F. A. A. (2015). The uses of colour vision: Ornamental, practical, and theoretical. Minds and Machines. doi:10.1007/s11023-015-9364-z.

Cohen, J. (2004). Color properties and color ascriptions: A relationalist manifesto. The Philosophical Review, 113(4), 451-506.

Cohen, J. (2009). The red and the real. Oxford: Oxford University Press.

Cohen, J. (2015). Ecumenicism, comparability, and color, or: How to have your cake and eat it, too. Minds and Machines. doi:10.1007/s11023-014-9354-6.

Cohen, J., Hardin, C. L., \& McLaughlin, B. P. (2006). True colours. Analysis, 66(4), 335-340.

Cohen, J., Hardin, C. L., \& McLaughlin, B. P. (2007). The truth about 'the truth about true blue'. Analysis, 67(2), 162-166.

Gegenfurtner, K. R., Bloj, M., \& Toscani, M. (2015). The many colours of 'the dress'. Current Biology (in press).

Gert, J. (2008). What colors could not be: An argument for color primitivism. Journal of Philosophy, $105(3), 128-157$.

Gert, J. (2010). Color constancy, complexity, and counterfactual. Nô̂s, 44(4), 669-690.

Hardin, C. (1988). Color for philosophers (1st ed.). Indianapolis, Indiana: Hackett.

Hilbert, D. (1987). Color and color perception: A study in anthropocentric realism. Stanford: Stanford University CSLI.

Johnson, K., \& Wright, W. (2006). Colors as properties of the special sciences. Erkenntnis, 64, 139-168.

Johnston, M. (1992). How to speak of the colors. Philosophical Studies, 68(3), 221-264.

Kalderon, M. (2007). Color pluralism. Philosophical Review, 116(4), 563-601.

Matthen, M. (1988). Biological functions and perceptual content. Journal of Philosophy, 85, 5-27.

Matthen, M. (2009). Truly blue: An adverbial aspect of perceptual representation. Analysis, 69(1), 48-54.

Shevell, S., \& Kingdom, F. (2008). Color in complex scenes. The Annual Review of Psychology, 59, $143-166$.

Stokes, D., Matthen, M., \& Biggs, S. (2014). Perception and its modalities. Oxford: Oxford University Press. 
Thompson, E. (1995). Colour vision. London: Routledge.

Tye, M. (2000). Consciousness, color, and content. Cambridge, Mass: MIT Press.

Tye, M. (2006a). The puzzle of true blue. Analysis, 66, 173-178.

Tye, M. (2006b). The truth about true blue. Analysis, 66, 340-344.

Tye, M. (2007). True blue redux. Analysis, 67(1), 92-93.

Watkins, M. (2002). Rediscovering colors: A study in pollyanna realism. Dordrecht: Kluwer.

Watkins, M. (2005). Seeing red: The metaphysics of color without the physics. Australasian Journal of Philosophy, 83, 33-52. 